\title{
PENERAPAN METODE STAD UNTUK MENINGKATKAN MOTIVASI DAN HASIL BELAJAR BAHASA INGGRIS DI KELAS XI IPA. 3 SMA NEGERI 1 BANDAR BARU
}

\author{
Mardiana \\ SMAN 1 Bandar Baru \\ e-mail : mar_mardiana@yahoo.com
}

\begin{abstract}
ABSTRAK
Penelitian ini bertujuan untuk mengetahui peningkatan motivasi belajar yang pada akhirnya akan meningkatkan hasil belajar siswa pada pembelajaran Bahasa Inggris Kelas XI IPA. 3 dengan penerapan cooperative learning STAD (Student Team Achievment Division) pada di SMA Negeri 1 Bandar Baru, semester II tahun ajaran 2013/2014. Jenis penelitian ini termasuk penelitian action research. Subyek penelitian ini adalah siswa Kelas XI IPA. 3 di SMA Negeri 1 Bandar Baru. Hasil penelitian ini menunjukkan: Melalui hasil penelitian tindakan kelas pada SMA Negeri 1 Bandar Baru terjadi peningkatan motivasi belajar yaitu pada siklus I rata-rata sebesar 65,77 sedangkan pada siklus II sebesar 80,38. Sebelum dilakukan pembelajaran dengan Metode STAD (Student Team Achievment Division) nilai siswa adalah 61,35. Pada siklus I hasil evaluasi siswa pada mata pelajaran Bahasa Inggris mendapatkan nilai rata-rata 68,85, Sementara itu, aktivitas belajar siswa dan performansi guru memperoleh nilai 64,80\% dan 62,50\% sedangkan pada siklus II mendapatkan nilai rata-rata 77,31. Dari penelitian tersebut terjadi peningkatan ketuntasan belajar sebesar pada siklus I sebesar $46 \%$ dan pada siklus II sebesar $88 \%$. Aktivitas belajar siswa meningkat menjadi $73,00 \%$, sedangkan performansi guru meningkat menjadi 87,50 Dengan demikian, dapat disimpulkan bahwa dilaksanakannya penelitian tindakan kelas melalui Metode cooperative learning STAD (Student Team Achievment Division) terhadap pembelajaran Bahasa Inggris pada dapat meningkatkan motivasi belajar yang dengan sendirinya dapat meningkatkan hasil belajar pada siswa Kelas XI IPA. 3 SMA Negeri 1 Bandar Baru.
\end{abstract}

Kata Kunci: Metode Cooperative Learning STAD (Student Team Achievment Division) Hasil Belajar Bahasa Inggris

\begin{abstract}
This study aims to determine the increase in learning motivation which will ultimately improve student learning outcomes in learning English Class XI Science. 3 by implementing the STAD (Student Team Achievement Division) cooperative learning in SMA 1 Bandar Baru, the second semester of the 2013/2014 school year. This type of research includes action research. The subjects of this study were students of Class XI Science. 3 in SMA Negeri 1 Bandar Baru. The results of this study indicate: Through the results of classroom action research at Bandar Baru 1 High School there was an increase in learning motivation, namely in the first cycle the average was 65.77 while in the second cycle it was 80.38. Before learning is done with the STAD Method (Student Team Achievement Division) the student score is 61.35. In the first cycle the results of student evaluations on English subjects get an average score of 68.85, meanwhile, student learning activities and teacher performance obtain a value of $64.80 \%$ and $62.50 \%$ while in the second cycle get an average score of 77,31 . From the study there was an increase in learning completeness as much as in the first cycle of $46 \%$ and in the second cycle was $88 \%$. Student learning activities increased to $73.00 \%$, while teacher performance increased to 87.50 Thus, it can be concluded that the implementation of classroom action research through the STAD (Student Team Achievement Division) cooperative learning method for learning English in order to increase learning
\end{abstract}


motivation with itself can improve learning outcomes for students of Class XI Science. 3 SMA Negeri 1 Bandar Baru.

Keywords: STAD Cooperative Learning Method (Student Team Achievement Division) Results of Learning English

\section{LATAR BELAKANG}

Dalam Undang-Undang Republik Indonesia No. 20 Tahun 2003 tentang Sistem Pendidikan Nasional Bab II Pasal 3 dinyatakan bahwa pendidikan nasional berfungsi mengembangkan kemampuan dan membentuk watak serta peradaban bangsa yang bermartabat dalam rangka mencerdaskan bangsa, bertujuan untuk mengembangkan potensi siswa agar menjadi manusia yang beriman dan bertakwa kepada Tuhan Yang Maha Esa, berakhlak mulia, sehat, berilmu, cakap, kreatif, dan menjadi warga negara yang demokratis serta bertanggung jawab. Pernyataan tersebut sesuai dengan salah satu tujuan nasional bangsa Indonesia yang tercantum dalam Pembukaan Undang-Undang Dasar Negara Republik Indonesia Tahun 1945, yaitu mencerdaskan kehidupan bangsa. Terkait dengan tujuan nasional tersebut, pemerintah secara bertahap berusaha meningkatkan kualitas pendidikan di setiap jenjang pendidikan.

Untuk membentuk generasi penerus bangsa sesuai kriteria yang diharapkan, pembelajaran Bahasa Inggris di SMA tentu tidak hanya mengutamakan kemampuan kognitif siswa. Kemampuan afektif siswa juga penting untuk dikembangkan, bahkan merupakan aspek yang dibidik dalam kegiatan pembelajaran Bahasa Inggris. Sebaliknya, dalam bidang ini aspek psikomotor memiliki peran yang berbeda. Ranah psikomotor tidak begitu banyak dilibatkan dalam pelaksanaan pembelajaran Bahasa Inggris karena lebih mengutamakan unjuk kerja dan kemampuan motorik siswa.

Berdasarkan uraian tersebut, penting bagi guru untuk melibatkan aspek kognitif dan afektif pada pembelajaran Bahasa Inggris. Salah satu cara yang dapat ditempuh yaitu dengan cara mengadakan perubahan pada kegiatan belajar mengajar di kelas Pada kenyataan di lapangan, selama ini pembelajaran Bahasa Inggris di sekolah masih berlangsung secara konvensional. Guru menggunakan metode ceramah untuk menyampaikan materi sementara siswa duduk mendengarkan dan sesekali mencatat. Sebenarnya ceramah dapat digunakan sebagai sarana menyampaikan materi, tetapi kurang dapat menarik minat siswa. Dapat dikatakan bahwa materi sudah diberikan, tetapi belum dapat diterima dengan baik. Dalam konteks ini, aspek kognitif masih diutamakan sedangkan aspek afektif belum begitu diperhitungkan. Dengan demikian, pembelajaran belum mampu membangkitkan rasa ingin tahu dan mengasah kemampuan afektif siswa. Permasalahan yang demikian terjadi pada ulangan harian pembelajaran Bahasa Inggris pada siswa Kelas XI IPA. 3 SMA Negeri 1 Bandar Baru. Dengan Kriteria Ketuntasan Minimal (KKM) 70 untuk mata pelajaran Bahasa Inggris, dari jumlah 26 orang siswa terdapat 6 atau $23 \%$ siswa berhasil memenuhi KKM, sedangkan 20 atau $77 \%$ siswa belum mencapai KKM. Banyaknya siswa yang belum tuntas menyebabkan rendahnya rata-rata kelas yaitu 61,35. Hal ini perlu segera ditangani agar tujuan pembelajaran Bahasa Inggris dapat terlaksana dengan baik. Oleh karena itu, diperlukan model pembelajaran yang sesuai dengan tujuan Bahasa Inggris.

Model pembelajaran kooperatif tipe Student Team Achievement Division (STAD) merupakan salah satu alternatif model pembelajaran yang dapat diterapkan dalam pembelajaran Bahasa Inggris. Model pembelajaran ini mengajak siswa bekerja sama dalam sebuah kelompok untuk memecahkan persoalan yang mereka hadapi. Guru membagi kelas menjadi kelompokkelompok yang heterogen untuk meminimalisir terjadinya kesenjangan antarsiswa. Selama kegiatan kelompok 
berlangsung, guru membimbing setiap kelompok berdiskusi. Pembelajaran ini tidak hanya membantu guru mentransfer ilmu pengetahuan. Siswa dapat meningkatkan keberanian, belajar menghargai orang lain, dan sikap tolong-menolong dalam beberapa perilaku sosial. Dengan menerapkan model pembelajaran STAD ini, diharapkan hasil belajar siswa Kelas XI IPA. 3 SMA Negeri 1 Bandar Baru dapat meningkat.

\section{METODE PENELITIAN}

Penelitian ini bermaksud mengungkapkan suatu upaya memperbaiki proses pembelajaran dengan menggunakan metode STAD untuk meningkatkan motivasi dan hasil belajar bahasa inggris di kelas XI IPA. 3 SMA Negeri 1 Bandar Baru,maka penggunaan pendekatan penelitian tindakan kelas (PTK) dipandang relevan dalam penelitian ini.

Penelitian Tindakan kelas terdiri dari tiga kata,yaitu "penelitian", "tindakan", dan "kelas". Penelitian adalah kegiatan mencermati suatu objek dengan menggunakan aturan metodologi tertentu untuk memperoleh data atau informasi yang bermanfaat untuk meningkatkan mutu suatu hal menarik minat dan penting bagi peneliti. Tindakan adalah suatu gerak kegiatan yang sengaja dilakukan dengan tujuan tertentu, yang dalam penelitian berbentuk rangkaian siklus kegiatan. Kelas adalah sekelompok siswa yang dalam waktu yang sama menerima pelajaran yang sama oleh guru. (Ansori $2009: 5$ )

Penelitian tindakan kelas dapat didefenisikan sebagai suatu penelitian tindakan yang dilakukan oleh guru sekaligus sebagai peneliti dikelasnya atau bersamasama dengan orang lain atau kolaborasi dengan jalan merancang, melaksa nakan dan merefleksikan tindakan secara kolaboratif dan partisipatif yang bertujuan untuk memperbaiki atau meningkatkan mutu atau kualitas proses pembelajaran dikelasnya melalui suatu tindakan tertentu dalam suatu siklus.(Kunandar 2009 : 45)
Penelitian ini dilakukan di SMA N 1 Bandar Baru Pidie Jaya, dan adapun subjek penelitian ini adalah siswa-siswi kelas $\mathrm{V}$ yang berjumlah 26 orang. Dalam penelitian tindakan ini, teknik pengumpulan data yang digunakan penulis adalah. Peneliti membuat Lembar observasi atau pengamatan sehubungan dengan apa yang telah ditetapkan. Hasil observasi ini merupakan gambaran keadaan umum didalam kelas selama pembelajaran meliputi kegiata guru maupun aktivitas belajar siswa. Indikator aktivitas siswa dikembangkan sendiri oleh peneliti yang diadaptasi dari Sardiman (2009 : 101), yang dibatasi pada aspek : (a) visual activities (memperhatiakn), (b) Oral activities ( berbicara), (c) Listening activities (mendengarkan), (d) writing activities (menulis), (e) Mental activities, dan (f) Emotional activities (emosional).

\section{HASIL PENELITIAN DAN PEMBAHASAN}

Pembelajaran pada kondisi awal di Kelas XI IPA. 3 SMA Negeri 1 Bandar Baru Kec. Bandar Baru Kabupaten Pidie Jaya, belum efektif dikarenakan pembelajaran masih berpusat pada guru. Dalam kegiatan belajar mengajar guru cenderung menggunakan pembelajaran model ceramah, sehingga siswa menjadi jenuh.

Dengan demikian motivasi belajar siswa sangat hal ini menyebabkan kurang efektifnya proses belajar mengajar dikelas tersebut. Sehingga menurunnya hasil belajar siswa dan bahkan masih bayak siswa yang mendapatkan nilai di bawah nilai KKM yang sudah ditentukan sekolah yaitu 70 .

Pelaksanaan kegiatan belajar mengajar untuk pra siklus dilaksanakan pada tanggal 06 Januari 2014 di Kelas Kelas XI IPA. 3 SMA Negeri 1 Bandar Baru dengan jumlah siswa 26 siswa. Dalam hal ini peneliti bertindak sebagai guru. Adapun proses belajar mengajar mengacu pada rencana pelajaran yang telah dipersiapkan. Pengamatan (observasi) dilaksanakan bersamaan dengan pelaksaaan belajar mengajar 
Pada akhir proses belajar mengajar siswa diberi tes formatif I dengan tujuan untuk mengetahui tingkat keberhasilan siswa dalam proses belajar mengajar yang telah dilakukan. Adapun data hasil penelitian pada pra siklus adalah sebagai berikut:

\section{Deskripsi Hasil Penelitian Pra Siklus}

Pembelajaran pada kondisi awal di Kelas XI IPA. 3 SMA Negeri 1 Bandar Baru Kec. Bandar Baru Kabupaten Pidie Jaya, belum efektif dikarenakan pembelajaran masih berpusat pada guru. Dalam kegiatan belajar mengajar guru cenderung menggunakan pembelajaran model ceramah, sehingga siswa menjadi jenuh.

Dengan demikian motivasi belajar siswa sangat hal ini menyebabkan kurang efektifnya proses belajar mengajar dikelas tersebut. Sehingga menurunnya hasil belajar siswa dan bahkan masih bayak siswa yang mendapatkan nilai di bawah nilai KKM yang sudah ditentukan sekolah yaitu 70 .

Pelaksanaan kegiatan belajar mengajar untuk pra siklus dilaksanakan pada tanggal 06 Januari 2014 di Kelas Kelas XI IPA. 3 SMA Negeri 1 Bandar Baru dengan jumlah siswa 26 siswa. Dalam hal ini peneliti bertindak sebagai guru. Adapun proses belajar mengajar mengacu pada rencana pelajaran yang telah dipersiapkan. Pengamatan (observasi) dilaksanakan bersamaan dengan pelaksaaan belajar mengajar

Pada akhir proses belajar mengajar siswa diberi tes formatif I dengan tujuan untuk mengetahui tingkat keberhasilan siswa dalam proses belajar mengajar yang telah dilakukan. Adapun data hasil penelitian pada pra siklus adalah sebagai berikut:

Tabel 1 Ketuntasan Belajar Siswa Hasil Tes Pra Siklus

\begin{tabular}{|l|c|c|}
\hline \multirow{2}{*}{ Prestasi Belajar } & \multicolumn{2}{|c|}{$\begin{array}{c}\text { Hasil Tes Siklus I } \\
\text { (Skor Dasar) }\end{array}$} \\
\cline { 2 - 3 } & $\begin{array}{c}\text { Banyak } \\
\text { Siswa }\end{array}$ & $\begin{array}{c}\text { Persentase } \\
(\%)\end{array}$ \\
\hline $\begin{array}{l}\text { Jumlah siswa } \\
\text { tuntas belajar } \\
(\text { skor } \geq 70)\end{array}$ & 6 & $23 \%$ \\
\hline
\end{tabular}

\begin{tabular}{|lr|r|r|}
\hline $\begin{array}{lr}\text { Jumlah } \\
\text { tidak } r \begin{array}{rl}\text { siswa } \\
\text { tuntas } \\
\text { belajar }\end{array}\end{array}$ skor $\left.\leq 70\right)$ & 20 & $77 \%$ \\
\hline Rata-rata kelas & \multicolumn{2}{|c|}{$\mathbf{6 1 , 3 5}$} \\
\hline
\end{tabular}

\section{Deskripsi Hasil Penelitian Siklus I}

Hasil Penelitian pada siklus I dapat dilihat seperti pada tabel dibawah ini

Tabel 2. Data Hasil Observasi Aktivitas Belajar Siswa Siklus I

\begin{tabular}{|c|l|c|c|}
\hline No & $\begin{array}{l}\text { Indikator yang } \\
\text { diamati }\end{array}$ & Skor & Persentase \\
\hline 1 & $\begin{array}{l}\text { Keantusiasan } \\
\text { siswa } \\
\text { mengikuti } \\
\text { pembelajaran }\end{array}$ & 69 & 66 \\
\hline 2 & $\begin{array}{l}\text { Keaktifan siswa } \\
\text { dalam bertanya } \\
\text { kepada guru }\end{array}$ & 64 & 62 \\
\hline 3 & $\begin{array}{l}\text { Keberanian } \\
\text { siswa dalam } \\
\text { mempresentasi } \\
\text { kan hasil } \\
\text { diskusinya }\end{array}$ & 65 & 63 \\
\hline 4 & $\begin{array}{l}\text { Kemampuan } \\
\text { siswa bekerja } \\
\text { sama dalam } \\
\text { kelompok }\end{array}$ & 67 & 64 \\
\hline 5 & $\begin{array}{l}\text { Keberanian } \\
\text { siswa dalam } \\
\text { mengemukakan } \\
\text { tanggapan atau } \\
\text { pendapat }\end{array}$ & 62 \\
\hline Jumlah total perolehan skor & 324 \\
\hline
\end{tabular}

Tabel 3 Hasil Observasi Keterampilan Guru Siklus I

\begin{tabular}{|c|l|c|}
\hline No & Indikator yang diamati & Skor \\
\hline 1 & Membuka pembelajaran & 3 \\
\hline 2 & $\begin{array}{l}\text { Menyampaikan materi } \\
\text { pembelajaran STAD }\end{array}$ & 2 \\
\hline
\end{tabular}




\begin{tabular}{|c|l|c|}
\hline 3 & $\begin{array}{l}\text { Melakukan variasi } \\
\text { dalam proses } \\
\text { pembelajaran }\end{array}$ & 3 \\
\hline 4 & $\begin{array}{l}\text { Membimbing siswa } \\
\text { dalam berdiskusi dengan } \\
\text { kelompoknya (Team } \\
\text { Study) }\end{array}$ & 2 \\
\hline 5 & $\begin{array}{l}\text { Pengkondisian kelas } \\
\text { selama pembelajaran }\end{array}$ & 3 \\
\hline 6 & $\begin{array}{l}\text { Membimbing presentasi } \\
\text { kelompok (Student } \\
\text { Creative) }\end{array}$ & 3 \\
\hline 7 & $\begin{array}{l}\text { Memberikan penguatan } \\
\text { kepada hasil pekerjaan } \\
\text { siswa(Team Score and } \\
\text { Team Recognition) }\end{array}$ & 2 \\
\hline 8 & $\begin{array}{l}\text { Menutup pelajaran ( } \\
\text { Whole Class units, Fact } \\
\text { Test }\end{array}$ & 20,00 \\
\hline Jumlah total perolehan skor & $62,50 \%$ \\
\hline \multicolumn{2}{|c|}{ Persentase } \\
\hline
\end{tabular}

Tabel 4. Ketuntasan Belajar Siswa Hasil Tes Siklus I

\begin{tabular}{|l|c|c|}
\hline \multirow{2}{*}{ Prestasi Belajar } & \multicolumn{2}{|c|}{$\begin{array}{c}\text { Hasil Tes Siklus I } \\
\text { (Skor Dasar) }\end{array}$} \\
\cline { 2 - 3 } & $\begin{array}{c}\text { Banyak } \\
\text { Siswa }\end{array}$ & $\begin{array}{c}\text { Persentase } \\
(\%)\end{array}$ \\
\hline $\begin{array}{l}\text { Jumlah siswa } \\
\text { tuntas belajar } \\
\text { (skor } \geq \text { 70) }\end{array}$ & 12 & $46 \%$ \\
\hline $\begin{array}{l}\text { Jumlah siswa } \\
\text { tidak tuntas } \\
\text { belajar (skor } \leq \\
\text { 70) }\end{array}$ & 14 & $54 \%$ \\
\hline Rata-rata kelas & \multicolumn{2}{|c|}{$\mathbf{6 8 , 8 5}$} \\
\hline
\end{tabular}

\section{Deskripsi Hasil Penelitian Siklus II}

Pelaksanaan kegiatan belajar mengajar pada siklus I ini masih terdapat kekurangan, sehingga perlu adanya revisi untuk dilakukan pada siklus berikutnya Pada kegiatan Siklus II tahapan tahapan yang peneliti lakukan tidak berbeda dengan yang peneliti lakukan pada Siklus I yaitu Perencanaan, Pelaksanaan, Observasi dan Monitoring sehingga pada siklus II di dapatkan hasil sebagai berikut:

Tabel 5. Data Hasil Observasi Aktivitas Belajar Siswa Siklus II

\begin{tabular}{|c|c|c|c|}
\hline No & $\begin{array}{c}\text { Indikator } \\
\text { yang diamati }\end{array}$ & Skor & Persentase \\
\hline 1 & $\begin{array}{l}\text { Keantusiasan } \\
\text { siswa } \\
\text { mengikuti } \\
\text { pembelajaran }\end{array}$ & 78 & 75 \\
\hline 2 & $\begin{array}{l}\text { Keaktifan } \\
\text { siswa dalam } \\
\text { bertanya } \\
\text { kepada guru }\end{array}$ & 76 & 73 \\
\hline 3 & $\begin{array}{l}\text { Keberanian } \\
\text { siswa dalam } \\
\text { mempresenta } \\
\text { sikan hasil } \\
\text { diskusinya }\end{array}$ & 74 & 71 \\
\hline 4 & $\begin{array}{l}\text { Kemampuan } \\
\text { siswa bekerja } \\
\text { sama dalam } \\
\text { kelompok }\end{array}$ & 74 & 71 \\
\hline 5 & $\begin{array}{l}\text { Keberanian } \\
\text { siswa dalam } \\
\text { mengemukak } \\
\text { an tanggapan } \\
\text { atau pendapat }\end{array}$ & 78 & 75 \\
\hline \multicolumn{3}{|c|}{$\begin{array}{c}\text { Jumlah total perolehan } \\
\text { skor }\end{array}$} & 365 \\
\hline \multicolumn{3}{|c|}{ Persentase } & $73,00 \%$ \\
\hline
\end{tabular}

Tabel 6.Hasil Observasi Keterampilan Guru Siklus II

\begin{tabular}{|c|l|c|}
\hline No & Indikator yang diamati & Skor \\
\hline 1 & $\begin{array}{l}\text { Membuka } \\
\text { pembelajaran }\end{array}$ & 3 \\
\hline 2 & $\begin{array}{l}\text { Menyampaikan materi } \\
\text { pembelajaran STAD }\end{array}$ & 4 \\
\hline
\end{tabular}




\begin{tabular}{|c|l|c|}
\hline 3 & $\begin{array}{l}\text { Melakukan variasi } \\
\text { dalam proses } \\
\text { pembelajaran }\end{array}$ & 4 \\
\hline 4 & $\begin{array}{l}\text { Membimbing siswa } \\
\text { dalam berdiskusi } \\
\text { dengan kelompoknya } \\
\text { (Team Study) }\end{array}$ & 3 \\
\hline 5 & $\begin{array}{l}\text { Pengkondisian kelas } \\
\text { selama pembelajaran }\end{array}$ & 4 \\
\hline 6 & $\begin{array}{l}\text { Membimbing } \\
\text { presentasi kelompok } \\
\text { (Student Creative) }\end{array}$ & 4 \\
\hline 7 & $\begin{array}{l}\text { Memberikan penguatan } \\
\text { kepada hasil pekerjaan } \\
\text { siswa(Team Score and } \\
\text { Team Recognition) }\end{array}$ & 3 \\
\hline 8 & $\begin{array}{l}\text { Menutup pelajaran ( } \\
\text { Whole Class units, Fact } \\
\text { Test }\end{array}$ & 3 \\
\hline Jumlah total perolehan skor & 28,00 \\
\hline \multicolumn{2}{|c|}{ Persentase } \\
\hline \multicolumn{2}{|l|}{}
\end{tabular}

Tabel 7. Ketuntasan Belajar Siswa Hasil Tes Siklus II

\begin{tabular}{|c|c|c|}
\hline \multirow{2}{*}{$\begin{array}{l}\text { Prestasi } \\
\text { Belajar }\end{array}$} & \multicolumn{2}{|c|}{$\begin{array}{c}\text { Hasil Tes Siklus I (Skor } \\
\text { Dasar) }\end{array}$} \\
\hline & $\begin{array}{l}\text { Banyak } \\
\text { Siswa }\end{array}$ & $\begin{array}{c}\text { Persentase } \\
(\%)\end{array}$ \\
\hline $\begin{array}{l}\text { Jumlah siswa } \\
\text { tuntas belajar } \\
\text { (skor } \geq 70)\end{array}$ & 23 & $88 \%$ \\
\hline $\begin{array}{l}\text { Jumlah siswa } \\
\text { tidak tuntas } \\
\text { belajar (skor } \leq \\
70 \text { ) }\end{array}$ & 3 & $12 \%$ \\
\hline $\begin{array}{l}\text { Rata-rata } \\
\text { kelas }\end{array}$ & \multicolumn{2}{|c|}{77,31} \\
\hline
\end{tabular}

Tabel 4.8 Rangkuman Ketuntasan Belajar Selama Dua Siklus

\begin{tabular}{|c|c|c|c|c|c|c|c|}
\hline \multirow{2}{*}{$\begin{array}{c}\text { N } \\
\text { o }\end{array}$} & \multirow{2}{*}{$\begin{array}{c}\text { Hasil } \\
\text { Tes } \\
\text { akhir }\end{array}$} & $\begin{array}{c}\text { Test } \\
\text { Aw } \\
\text { al }\end{array}$ & $\begin{array}{c}\text { Jumlah/Persentase Ketuntasan } \\
\text { us } \\
\text { I }\end{array}$ & $\begin{array}{c}\text { Sikl } \\
\text { us } \\
\text { II }\end{array}$ & $\%$ \\
\hline 1. & $\begin{array}{l}\text { Siswa } \\
\text { yang } \\
\text { tuntas }\end{array}$ & 6 & $\begin{array}{c}\text { 23 } \\
\%\end{array}$ & 12 & $\%$ & 23 & $\%$ \\
\hline
\end{tabular}

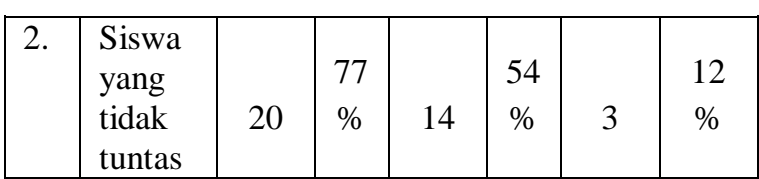

\section{Kesimpulan}

Dari hasil kegiatan pembelajaran yang telah dilakukan selama dua siklus, dan berdasarkan seluruh pembahasan serta analisis yang telah dilakukan oleh peneliti dengan dibantu tim peneliti maka dapat disimpulkan sebagai berikut:

1. Penerapan metode STAD memiliki dampak positif dalam meningkatkan prestasi belajar siswa yang ditandai dengan peningkatan ketuntasan belajar siswa dalam setiap siklus, yaitu siklus I (46\%), dan siklus II (88\%).

2. Penerapan metode STAD mempunyai pengaruh positif, yaitu dapat meningkatkan motivasi belajar siswa dalam belajar Bahasa Inggris, hal ini ditunjukan dengan antusias siswa yang menyatakan bahwa siswa tertarik dan berminat dengan metode STAD sehingga mereka menjadi termotivasi untuk belajar.

3. Penerapan metode STAD memiliki dampak positif terhadap kerjasama antara siswa, hal ini ditunjukkan adanya tanggung jawab dalam kelompok dimana siswa yang lebih mampu mengajari temannya yang kurang mampu. Siswa senang dan tertantang dalam menyelesaikan soal-soal yang diberikan oleh guru karena dapat mengembankan kemampuan kerja sama yang baik.

\section{Saran}

Dari hasil penelitian yang diperoleh dari uraian sebelumnya agar proses belajar mengajar Bahasa Inggris lebih efektif dan lebih memberikan hasil yang optimal bagi siswa, maka disampaikan saran sebagai berikut:

1. Untuk melaksanakan penerapan metode belajar kelompok memerlukan persiapan yang cukup matang, sehingga guru harus mampu menentukan atau memilih topik yang benar-benar bisa diterapkan dengan 
pembelajaran penerapan metode STAD dalam proses belajar mengajar sehingga diperoleh hasil yang optimal.

2. Dalam rangka meningkatkan prestasi belajar siswa, guru hendaknya lebih sering melatih siswa dengan berbagai metode pengajaran yang sesuai, walau dalam taraf yang sederhana, dimana siswa nantinya dapat menemukan pengetahuan baru, memperoleh konsep dan keterampilan, sehingga siswa berhasil atau mampu memecahkan masalah-masalah yang dihadapinya.

3. Untuk penelitian yang serupa hendaknya dilakukan perbaikan-perbaikan agar diperoleh hasil yang lebih baik.

\section{DAFTAR PUSTAKA}

Arikunto, Suharsimi dkk. 2009. Penelitian Tindakan Kelas. Jakarta: Bumi Aksara

Ansto Rahadi. (2003). Media Pembelajaran. Jakarta: Dikjen Dikti Depdikbud

Armstrong, Scott \& Jesse Palmer. 2011. Student Teams Achievement Divisions (STAD) in a twelfth grade classroom. Journal of Social Studies Research 22.1. Online. http://search.ebscohost.com.htm [diakses 28/01/14]

Kunandar. (2009). Langkah mudah penelitian Tindakan Kelas, Jakarta: Rajawali Pers. 